\title{
Exploratory Analysis of Plasma Neurotensin as a Novel Biomarker for Early Detection of Colorectal Polyp and Cancer
}

\author{
Shengyang Qiu ${ }^{1,2} \cdot$ Stella Nikolaou ${ }^{1,2} \cdot$ Francesca Fiorentino $^{1,3} \cdot$ Shahnawaz Rasheed $^{1,2} \cdot$ Ara Darzi $^{1}$. \\ David Cunningham ${ }^{2} \cdot$ Paris Tekkis ${ }^{1,2} \cdot$ Christos Kontovounisios $^{1,2}$
}

Received: 18 March 2019 / Accepted: 16 April 2019 / Published online: 15 May 2019

(C) The Author(s) 2019

\begin{abstract}
Earlier detection of colorectal cancer (CRC) results in improved survival. Existing non-invasive biomarkers have suboptimal accuracy. Neurotensin (NTS) is involved in CRC carcinogenesis. This study evaluated the diagnostic potential of plasma NTS for colorectal polyps and cancers. Participants were selected based on national CRC referral guidelines. All subjects underwent colonoscopy. Average plasma concentrations were compared across different diagnostic groups. Predictors for detecting colorectal neoplasia were identified. Receiver operator characteristic (ROC) curve analysis assessed the diagnostic accuracy of NTS. An independent biobank was used as validation group. Of 165 participants, 46 had polyps or CRC. Significantly higher plasma NTS was found in the colonic neoplasia group $(603.6 \mathrm{pg} / \mathrm{ml} \mathrm{vs.} 407.2 \mathrm{pg} / \mathrm{ml}, p<0.01)$. Risk factors for colonic polyps or cancers included $\log _{\mathrm{e}}$ (plasma NTS concentration) (OR, 2.73; 95\% CI, 1.33-5.59, $\left.p<0.01\right), \log _{\mathrm{e}}$ (Age) (OR, 15.49; 95\% CI, $2.67-$ $89.66, p<0.01$ ) and cigarette smoking (OR, 3.49; 95\% CI, 1.31-9.26, $p=0.01)$. Plasma NTS had an optimal sensitivity of $60.4 \%$ and specificity of $71.6 \%$ for the diagnosis of colorectal polyps and cancers. Similar diagnostic accuracy was obtained in the validation group. Plasma NTS has the potential to be a non-invasive biomarker for colorectal neoplasia. It appears to be more accurate than existing blood markers and is unique in being able to detect precancerous polyps.
\end{abstract}

Keywords Colorectal neoplasia $\cdot$ Biomarker $\cdot$ Early detection

\section{Introduction}

Colorectal cancer (CRC) is a worldwide health problem that ranks third in incidence and fourth in mortality with an estimated 1.2 million cases and 0.6 million deaths annually. The natural history of CRC allows prevention by early detection of precancerous lesions. Earlier diagnosis of CRC results in better survival with 1-year survival of $98 \%$ compared with $40 \%$ for stage I and stage IV disease respectively [1]. Strategies for earlier detection include screening and earlier recognition of

Paris Tekkis

p.tekkis@imperial.ac.uk

1 Department of Surgery and Cancer, Imperial College London, Chelsea and Westminster Campus, 369 Fulham Road, London SW10 9NH, UK

2 Department of Colorectal Surgery, Royal Marsden Hospital, London, UK

3 Imperial Clinical Trials Unit, Imperial College London, London, UK cancer in symptomatic individuals. In the UK, the National Bowel Cancer Screening Programmes uses faecal occult blood (FOBT) test, flexible sigmoidoscopy and colonoscopy and virtual colonoscopy. Updated national referral guidelines for the recognition of cancer were introduced in 2016. A greater range of symptoms, with positive predictive value of $1 \%$, was incorporated in to the referral criteria [2]. Both of the above rely on colonoscopy, which remains the gold standard for the detection of colorectal neoplasia. An accurate and noninvasive alternative has been sought.

The last decades have been marked by the accumulation of knowledge about the inner workings of the normal and abnormal cells of the colon. The discovery and validation of novel assays is the source of new diagnostic modalities. In this context, we assess the reliability of the neurotensinergic system to cancer progression as well as the regulation and mechanism of the system in order to determine its potential in colorectal cancer diagnosis, surveillance and screening.

Neurotensin (NTS) is a 13-amino-acid peptide originally isolated by Garraway and Leeman [3]. NT has shown to exert numerous oncogenic effects involved in tumour growth and 
metastatic spread. These effects are mostly mediated by neurotensin receptor 1 (NTSR1) [4].

NTSR1 appears to be solely expressed in colonic cancer cells but not in normal colon cells $[5,6]$. The NTS/NTSR1 complex is an actor in cancer progression in human colonic adenomas and cancers [7, 8]. In in vitro studies, the addition of NT to human colon cancer cell lines resulted in significantly increased cancer cell growth and the growth of xenografted human colon cancer cells in mice [9]. In vivo, NTSR1 mRNA expression was undetectable in superficial differentiated epithelial cells in histological specimens of normal human colonic epithelium, but there was moderate and strong expression in adenomas and adenocarcinomas respectively. Tumours that infiltrated into and beyond the muscularis propria showed even higher expression [10].

Small-scale studies have shown elevated circulating NTS in peripheral blood in patients with CRC [11, 12]. A pilot study included 26 patients who underwent colonoscopy of whom 14 had colon pathology. Pathology in colon was associated with 3.7-fold increase in NTS levels. In multivariate analysis, patients with pathology in the colon have increased plasma NT levels compared with controls adjusted for age, gender, BMI and co-morbidities. After ROC curve analysis, NTS in plasma was associated with $87.5 \%$ sensitivity and 91.7\% specificity for discriminating the colon pathology from normal colonic epithelium. (AUC $=0.89395 \%$ CI; 0.749-1, $p=0.001$ ). This is in comparison to CEA, the most widely used CRC biomarker, which has a sensitivity of 36\% and a specificity of $87 \%$ for Dukes A and B colorectal cancers. [13] Furthermore, there are currently no blood markers for colonic polyps.

The aim of this study is to investigate whether plasma NTS could be a non-invasive diagnostic tool in the early detection of colorectal neoplasia. If validated, it could lead to the discovery of a non-invasive blood-based marker that could detect early stage. We conducted a large-scale prospective study to further investigate the diagnostic potential of plasma neurotensin as a diagnostic marker for colorectal polyps and cancers in patients who have symptoms which fulfil UK national criteria for suspected colorectal cancer [2].

\section{Patients and Methods}

A prospective, multicentre, double-blinded cohort study was setup with ethical approval from the Human Research Authority (REC reference 16/SC/0523). Eligible participants were those referred to undergo colonoscopy for symptoms suspicious for colorectal malignancy based on national referral guidelines for suspected colorectal cancers [2] or those having colonoscopy to confirm diagnosis of colorectal cancer. Exclusion criteria were patients aged 17 years or younger, medical or psychiatric conditions impairing ability to give informed consents; patients currently receiving cancer treatment e.g. on chemotherapy; patients who were pregnant, lactating, or undergoing fertility treatment; and patients who were being actively treated for another malignancy.

All patients who were referred to the study centres were screened for eligibility. After recruitment, baseline patient demographics collected included age, sex, BMI, comorbidities, regular medication, smoking and alcohol intake and medication history. Peripheral venous blood samples were prospectively collected and were anonymised to avoid bias during sample analysis. Eight millilitres of blood was collected from each patient into EDTA bottles. These samples were collected prior to patients undergoing colonoscopy or surgery. Patients were fasting for $24 \mathrm{~h}$ prior to sample collection. Blood samples were centrifuged for $15 \mathrm{~min}$ at $1000 \times g$ at $2-8{ }^{\circ} \mathrm{C}$ within 30 min of collection. Plasma was immediately aliquoted and stored at $-80^{\circ} \mathrm{C}$.

Furthermore, plasma samples stored in the Imperial College Healthcare Tissue Bank (ICHTB, Human Tissue Authority Licence: 12275, Research Ethics Committee Approval: 12/WA/0196, Tissue Bank Application number R16007) were used to cross validate the findings from the prospective study. The stored samples were collected from patients who match the inclusion criteria of this study. The samples were collected and stored between 2013 and 2015 . These samples were collected from non-fasting individuals.

A competitive enzyme immunoassay (ELISA) kit (catalogue number ABX152510, Abbexa Ltd., Cambridge, UK) was used to detect NTS as per the manufacturer's instructions. Standard protocol for ELISA was followed to ensure the accuracy of the results. Standard concentration curves were constructed for each individual assay. Close fit of the curve $\left(R^{2}>\right.$ 0.98 ) was achieved for all standard curves. Each sample was assayed multiple times to ensure consistency of results.

\section{Outcome Measures}

The primary outcome measure was the sensitivity and specificity of plasma NTS as a diagnostic marker for colorectal polyps or cancer. Secondary outcome measures were the differences in plasma NTS concentration between individuals with normal colons and different colonic pathologies, as well as risk factors for the presence of colonic pathologies in the study cohort.

\section{Statistical Analysis}

Based on published pilot data, in order to observe a two-sided $95 \%$ confidence interval of $75-95 \%$ for a sensitivity of $85 \%$, we needed to recruit 49 patients with colonic polyps or cancer [11]. Given reported polyp and cancer detection rates of 30\%, we estimated that 164 participants needed to be recruited to 
the study. Assuming a loss to follow-up of 5\%, we recruited 170 participants in total.

To minimise bias, researchers were blinded to the colonoscopy findings for each subject. The colonoscopic finding for each participant was retrieved from the electronic records of colonoscopy and histology reports after all sample analysis was complete. The diagnoses were categorised as abnormal, i.e. cancer, polyps (adenomatous and hyperplastic) or other benign pathology (colitis, diverticular disease), and normal.

A pre-specified statistical analysis plan was signed off before unblinding the data. Statistical analysis was performed using SPSS Statistics (version 20.0, IBM Corporation, USA). Median plasma neurotensin concentrations were compared using Mann-Whitney $U$ and Kruskal-Wallis tests across diagnoses groups. Univariate binary logistic regression was performed to identify risk factors for colonic pathology on colonoscopy. Normality was checked and where variables were non-normal, a log transformation was carried out prior to regression analysis. Risk factors with significance of $p<0.10$ were included in a multivariate regression model to identify those associated with colonic polyps/cancer. Finally, receiver operating characteristic (ROC) curve was constructed to determine the diagnostic accuracy of plasma NTS. The optimal cut-off of plasma NTS as well as the sensitivity and specificity of the test was calculated using the Youden index.

\section{Results}

One hundred and eighty patients were recruited between November 2016 and July 2017. Fifteen did not complete colonoscopy or were unable to provide plasma sample for analysis. All blood samples provided were taken immediately prior to undergoing colonoscopy. The median age of the remaining 165 patients was 61.5 years with an interquartile range (IQR) of 51.8-61.8 years. Eighty-four patients had normal colonoscopies and 81 had colonic pathologies. Of these, 46 had either colonic polyps or cancers. The median plasma NTS concentration and patient demographics between diagnostic groups are shown in Table 1 and Fig. 1. There were no adverse events from performing the blood test or reference tests. There was a significant difference between the plasma NTS concentrations across the diagnoses groups ( $p=0.04$, Kruskal-Wallis test). There was a significant difference between NTS concentration in individuals with normal colons (median $401.6 \mathrm{pg}$ / $\mathrm{ml}$ ) and those with colonic pathologies (median $550 \mathrm{pg} / \mathrm{ml}$ ). ( $p=0.03$, Mann-Whitney $U$ test). However, there was no significant difference between the normal colonoscopy group and the group of patients found to have colonic diverticulosis or inflammation. Therefore, the difference observed between the normal and abnormal colonoscopy groups was a result of the difference in NTS concentration of individuals with colonic neoplasia (polyps or cancers) and those without (Table 2).
The median plasma NTS level in those with colonic polyps (hyperplastic or adenomatous) or cancer was $603.6 \mathrm{pg} / \mathrm{ml}$, which was significantly different to individuals without polyps or cancer $(407.2 \mathrm{pg} / \mathrm{ml})(p<0.01$, independent samples Mann-Whitney $U$ test). After natural $\log$ transformation, significant difference remained between the polyp or cancer group and the non-polyp or cancer group $(p<0.01$, independent samples Student $t$ test).

There was no significant difference between the NTS plasma concentration in patients with polyps or cancer. ( $p=0.215$, Mann-Whitney $U$ test). When the NTS plasma concentration was compared between patients with colonic polyps or cancer in different locations within the colon (right, transvers, left, and rectum), there was no significant difference $(p=0.09$, Kruskal-Wallis Test).

Univariate binary logistic regression analysis showed age, smoking status and elevated plasma NTS were significant risk factors for detecting colorectal polyps or cancers on colonoscopy (Table 3). Multivariate binary regression analysis that demonstrated Log(Plasma NTS) was an independent risk factor for detecting colorectal neoplasia on colonoscopy $(p<0.01$, OR 2.73, 95\% CI 1.33-5.59) (Table 4).

ROC curve analysis of the diagnostic accuracy of plasma NTS for detecting colonic polyps or cancers showed an area under the curve (AUC) of $0.63(p<0.01)$ (Fig. 2a). The optimal cut-off was $550 \mathrm{pg} / \mathrm{ml}$ with a sensitivity of $60.4 \%$ and specificity of $71.6 \%$. The AUC for detecting colonic polyps was $0.67(p<0.01)$ with optimal cut-off of $534 \mathrm{pg} / \mathrm{ml}$. The sensitivity was $69.7 \%$ and specificity of $68.6 \%$ (Fig. 2b).

Analysis of 100 plasma samples obtained from the tissue bank again revealed significant difference between the plasma concentration of NTS between diagnostic groups $(p=0.03$, Kruskal-Wallis test). The median NTS concentration of patients with colonic neoplasia was $457 \mathrm{pg} / \mathrm{ml}$ compared with $338.9 \mathrm{pg} / \mathrm{ml}$ in those without polyps or cancer $(p=0.03$, Mann-Whitney $U$ test).

The median concentration of plasma NTS was $368.0 \mathrm{pg} / \mathrm{ml}$ in the tissue-banked samples compared with $447.6 \mathrm{pg} / \mathrm{ml}$ in the prospectively collected sample $(p<0.01$, Mann-Whitney $U$ test), similar diagnostic accuracy of plasma NTS for detecting colorectal polyps and cancers with the prospective cohort. The AUC was $0.69(p<0.01)$ with optimal sensitivity of $66.7 \%$ and specificity of $62.9 \%$ albeit with a lower cut-off of $376 \mathrm{pg} / \mathrm{ml}$ compared with the prospective cohort (Appendix Table 5).

\section{Discussion}

Currently, it has been estimated that there were 136,830 new cases of colorectal cancer (CRC) and 50,310 deaths due to $\mathrm{CRC}$ in the USA in 2014. In the European Union (EU), colorectal cancer is the third most common cancer and the second 
Table 1 Patient demographics and median plasma neurotensin concentration across diagnosis groups. IQR inter quartile range, ASA American Society of Anesthesiology grade, $\mathrm{pg} / \mathrm{ml}$ picograms per millilitre

\begin{tabular}{llllllll}
\hline Diagnosis & $\begin{array}{l}\text { Number } \\
\text { of cases }\end{array}$ & $\begin{array}{l}\text { Median } \\
\text { age (IQR) }\end{array}$ & $\begin{array}{l}\text { Sex } \\
\text { (male:female) }\end{array}$ & $\begin{array}{l}\text { Median } \\
\text { ASA }\end{array}$ & $\begin{array}{l}\text { Smoker } \\
(\%)\end{array}$ & $\begin{array}{l}\text { Median } \\
\text { BMI }\end{array}$ & $\begin{array}{l}\text { Median plasma } \\
\text { neurotensin } \\
\text { concentration (pg/ml) } \\
\text { (IQR) }\end{array}$ \\
\hline Normal & 84 & $55.1(50.6-66.8)$ & $37: 47$ & 2 & 12.9 & 24.5 & $402.1(280.7-601.8)$ \\
Diverticulosis & 19 & $67.0(60.6-72.6)$ & $7: 12$ & 2 & 11.8 & 23.3 & $464.1(300.1-714.0)$ \\
Colonic inflammation & 8 & $56.6(42.4-65.2)$ & $4: 4$ & 1 & 14.3 & 29.0 & $408.6(234.2-675.7)$ \\
Hyperplastic poly (s) & 7 & $60.1(54.2-72.3)$ & $4: 3$ & 1 & 40.0 & 27.1 & $536.3(340.5-633.3)$ \\
Adenomatous poly (s) & 26 & $67.4(61.2-78.2)$ & $8: 18$ & 2 & 44.4 & 23.5 & $641.2(507.6-774.7)$ \\
Cancer & 20 & $64.3(46.9-72.1)$ & $11: 9$ & 2 & 18.8 & 24.5 & $530.3(283.6-712.5)$ \\
\hline
\end{tabular}

leading cause of death, accounting for more than 345,000 new cases and 150,000 deaths in 2012. Survival is highly dependent on early diagnosis. Early detection of CRC can improve the 5-year survival rate from about $10 \%$ in stage IV disease to up to $90 \%$ in stage I disease [14]. Additionally, the adenoma to adenocarcinoma and serrated pathways in CRC is linear. Early detection of non-cancerous colonic lesions with prompt removal followed by surveillance can significantly reduce the incidence of CRC.

Colonoscopy remains the gold standard for diagnosis and screening of colorectal polyps. However, its invasive nature carries with it complications such as colonic perforation and bleeding. It also carries with it significant economic costs [15]. However, there appears to be high noncompliance rates in countries with colonoscopic bowel screening programmes $[15,16]$. FOBT and FIT are cheaper and non-invasive alternatives for screening of colorectal cancer. These have 60 to $80 \%$ sensitivity and 85 to $95 \%$ specificity [17]. For adenomas, the sensitivity and specificity for FIT was $18 \%$ and $95 \%$ [18]. Adherence to repeated FOBT is paramount in ensuring the robustness of screening but adherence to repeated FOBT is low [19]. There also appears to be a bias for poorer participation in lower socieoeconomic groups, when it is known that those in lower socioeconomic groups who present with CRC have more advanced disease and worse outcomes $[20,21]$. Blood markers such as CEA and cancer antigen (CA) 19-9 have sub-optimal sensitivity and specificity, are exclusively used as surveillance markers and are excluded from the screening recommendations [22]. More promising results have been published for genes deriving from peripheral blood mononuclear cells (PBMCs) including DNA methylation of specific genes, but validation in the clinical settings is awaited [23, 24].
Fig. 1 Plasma neurotensin concentration across different colorectal pathologies on colonoscopy

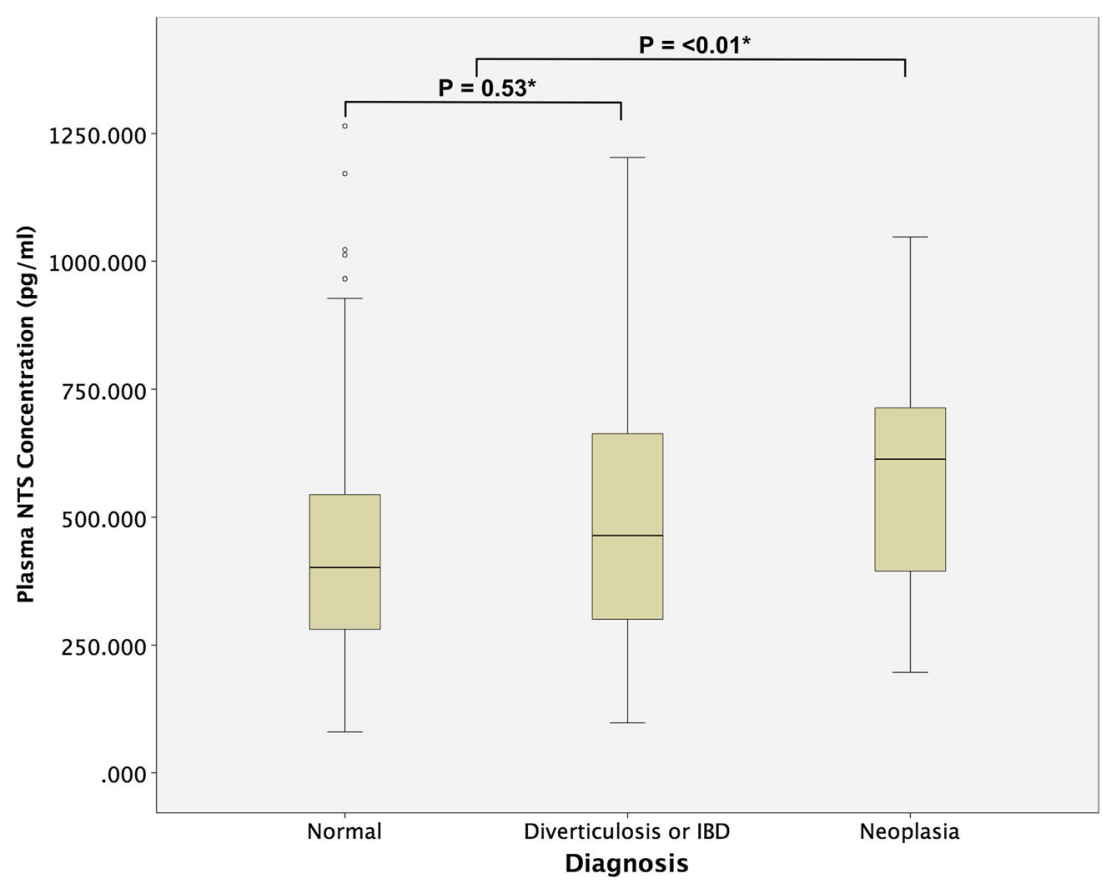


Table 2 Median plasma concentration between diagnostic groups. *Independent Mann-Whitney $U$ test. No colonic neoplasia group includes normal, diverticulosis and colonic inflammation. Colonic neoplasia group includes hyperplastic polyps, adenomatous polyps and colorectal cancer

\begin{tabular}{lll}
\hline Diagnosis & $\begin{array}{l}\text { Median plasma neurotensin } \\
\text { concentration }(\mathrm{pg} / \mathrm{ml})(\mathrm{IQR})\end{array}$ & \\
\hline Normal & $401.6(267.6-654.4)$ & $0.03^{*}$ \\
Abnormal & $550.6(339.6-712.5)$ & $0.53^{*}$ \\
Normal & $401.6(267.6-654.4)$ & \\
Diverticulosis or IBD & $464.1(299.9-714.0)$ & $<0.01^{*}$ \\
No colonic neoplasia & $407.2(287.3-648.5)$ & \\
Colonic neoplasia & $603.6(394.0-714.8)$ & \\
\hline
\end{tabular}

The ideal marker should have the following qualities: high sensitivity and specificity, it should be safe and non-invasive so that it can be broadly accepted by patients, cost effectiveness so that it can be easily adopted, easy to measure and should be detected among different genders and ethnic groups [25-27].

Some candidate proteins have been published as CRC diagnostic markers. A single protein marker, TIMP-1, has detected CRC with $42-65 \%$ sensitivity and $95 \%$ specificity [28]. Babel et al. reported 43 proteins that could distinguish between CRC patients and healthy controls [29]. These are awaiting clinical validation.

NTS and its receptors have been implicated in the progression of a broad range of human cancers. These include cancers of the breast, prostate, lung, liver and pancreas among others [30-34]. There is compelling evidence for the involvement of NTS and its receptors in the oncogenesis of human colorectal cancer [35]. NTS appears to promote cell growth in $\mathrm{CHO}$ cells transformed with human NTSR1 and in colon cancer HT29 cells [36]. It also stimulates growth in five different human cancer lines (SW480, SW620, HT29, HCT116 and C1.19A) that express NTSR1, but has no effect on cells with absent NTSR1 [5]. Gui et al. examined NTSR1 mRNA by in situ hybridization in normal colonic mucosa, adenomas and colonic adenocarcinomas. NTSR1 mRNA expression was found to be non-detectable in epithelial cells of normal colonic epithelium but adenomas and adenocarcinomas demonstrated moderate to strong expression $(p<0.05)$. There was higher level of expression in adenocarcinomas compared with adenomas $(p<0.05)$ [10].

This study is the first large-scale prospective clinical validation of plasma NTS level for the diagnosis of colonic polyps and cancers. The study demonstrated significantly higher plasma NTS levels in individuals with colonic neoplasia. NTS appears to have a sensitivity and specificity of 60 to $70 \%$ for colorectal cancers and polyps compared with CEA, where only $4 \%$ of patient with stage I CRC had elevated plasma levels [37]. It also appears to be unique in its ability to differentiate patients with colonic polyps with those without polyps.

Plasma NTS appears to have some potential as a screening, diagnostic and surveillance marker for colonic polyps and cancers. It has advantages over existing tests such as FBOT in its ease of use (single blood test versus multiple stool samples), as well as the ability of detecting pre-cancerous lesions in the colon. The result of this study also suggests the diagnostic ability is not affected by the fasting status of patients' plasma concentration from the biobanked samples, from patients who were not fasted, and had similar diagnostic efficacy compared with patients who were fasted in the prospectively collected sample. This study is also feasible to perform the assay in plasma samples that have been stored. Having said that, there is a clear difference between the plasma NTS concentration and these patient cohorts. This could be due to the aforementioned difference in fasting status or possibly due to the degradation of plasma NTS in stored samples. Further work is clearly needed to investigate the effect of fasting and storage on plasma NTS concentrations.

In both cohorts of samples, there was significant variation in levels of plasma NTS between individuals. There appears to be subsets of individuals with colonic polyps or cancers who do not have high levels of plasma NTS and individuals with high plasma NTS without any colonic lesions. This ultimately limits the diagnostic accuracy of plasma NTS. Further work is needed to clearly understand relationship between NTS expression in colonic
Table 3 Univariate binary logistic regression for risk factors for colonic polyps or cancers. *Binary logistic regression analysis. ${ }^{+}$Natural logarithmic transformation for non-normal variables applied. $\beta$ beta coefficient, S.E. standard error, 95\% CI 95\% confidence interval

\begin{tabular}{llllll}
\hline & $\beta$ & S.E. & Odds ratio & $95 \%$ CI & $p$ value \\
\hline Sex (male) & 0.00 & 0.34 & 1.00 & $0.51-1.05$ & $1.00^{*}$ \\
$\log _{e}($ age $)$ & 1.94 & 0.80 & 6.95 & $1.45-33.30$ & $0.0 *^{+}$ \\
$\mathrm{BMI}$ & 0.00 & 0.03 & 1.00 & $0.94-1.07$ & $0.93^{*}$ \\
$\mathrm{ASA}$ & 0.15 & 0.19 & 1.16 & $0.76-1.70$ & $0.44^{*}$ \\
Smoker & 0.96 & 0.44 & 2.61 & $1.01-6.23$ & $0.03^{*}$ \\
Log $_{\mathrm{e}}$ (units per week of alcohol) & 0.52 & 0.31 & 1.68 & $0.91-3.08$ & $0.10^{*}$ \\
Log $_{e}$ (plasma neurotensin concentration) & 0.90 & 0.35 & 2.47 & $1.24-4.85$ & $0.01 *^{+}$ \\
\hline
\end{tabular}

$p$ values are significant $<0.05$ 
Table 4 Multivariate regression of risk factors for colonic polyps or cancers. $\beta$ beta coefficient, S.E., standard error, $95 \%$ CI $95 \%$ confidence interval

\begin{tabular}{lllll}
\hline & $\beta$ & S.E. & Odds ratio & $95 \%$ CI \\
\hline $\log _{\mathrm{e}}$ (age) & 2.74 & 0.90 & 15.49 & $2.67-89.66$ \\
$\log _{\mathrm{e}}$ (plasma neurotensin concentration) & 1.004 & 0.37 & 2.73 & $1.33-5.59$ \\
Smoker & 1.249 & 0.499 & 3.49 & $1.31-9.26$ \\
\hline
\end{tabular}

neoplasia and its plasma concentration. In the multivariate regression model, NTS concentration was an independent risk factor for colonic polyps and cancers, along with cigarette smoking and advancing age. There may be other confounding factors which may result in differential expression of plasma NTS in individuals, understanding the cause versus effect relationship between presence of colonic neoplasia, and plasma NTS is important in improving the diagnostic ability of NTS. For example, does a high level of baseline NTS expression predisposes a certain individual to colonic hyperplasia and metaplasia, or are colonic neoplasia responsible for directly secreting or stimulating the secretion of NTS into blood. Multi-centre studies powered to include larger number CRC and polyps with concurrent examination of genetic expression of relevant genotypes as well as histological examination of expression of NTS and NTS receptors on neoplastic tissue are required to answer these questions.

As a result of the small number of CRC patients recruited into the study, it was not possible to determine if there are any significant differences of plasma NTS concentration in individuals with $\mathrm{CRC}$ and those with polyps. In the prospective cohort, the NTS concentration appeared lower in the CRC group compared with the polyp group. This is in contrast to the findings in the biobanked samples. The inclusion criteria for this study were all patients who were referred for suspected CRC based on national guidelines. The low positive predictive values of the referral criteria resulted in low CRC diagnostic yield. The CRC cases were also heterogeneous in terms of their location in the colon as well as histological grade. Both of these factors may affect plasma NTS level. Continued sample collection in order to obtain an adequate sample of $\mathrm{CRC}$ is required to draw conclusions.

In order to evaluate the potential of using plasma NTS as a screening marker, future studies must evaluate this marker in the setting of asymptomatic individuals. Likewise, its use as a surveillance marker will require serial evaluation of plasma NTS in individuals before and after treatment of colorectal neoplasia (i.e. polypectomy or $\mathrm{CRC}$ resection).
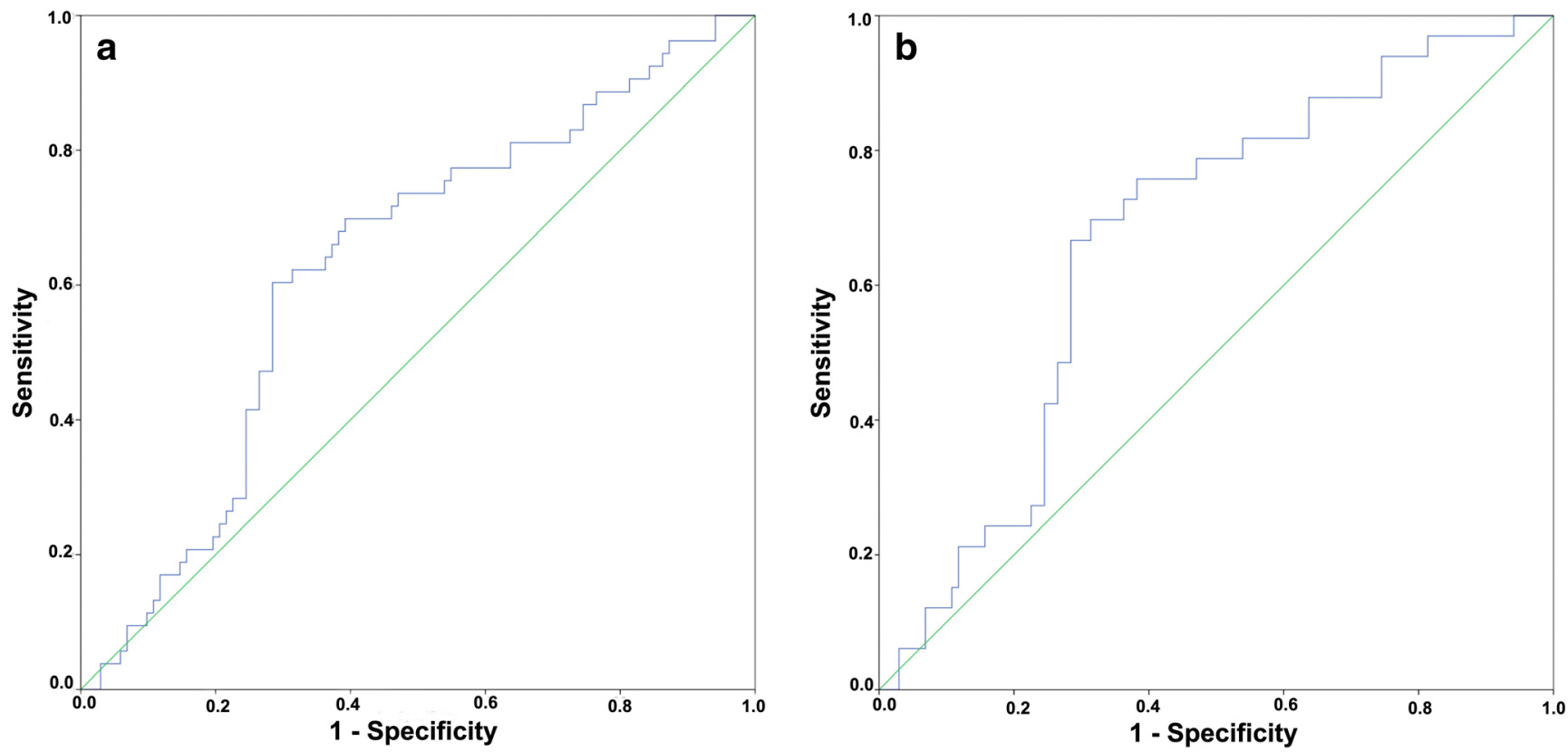

Fig. 2 Receiver operator characteristic curves for diagnostic accuracy of plasma neurotensin for detecting colorectal polyps and cancers (a) and colorectal polyps (b) 


\section{Conclusion}

NTS plasma concentration appears to have the potential to differentiate individuals with colonic neoplasia with those who do not. Furthermore, it has the potential to detect patients with colorectal polyps as well as CRC. The use of NTS blood test as a diagnostic adjunct for colonic polyps and cancers could offer an advantage over existing diagnostic modalities. Therefore, it warrants further validation, along the biomarker development roadmap, in order for it to be incorporated into future clinical practice.

Acknowledgments The authors would like to acknowledge Mr. Jeffrey Lordan for his help in this study.

Authors' Contributions All authors had substantial contributions to the conception or design of the work; SQ, CK and SN contributed to the acquisition of data. SQ, CK, FF and PT contributed to the analysis and interpretation of data for the work.

SQ, CK and PT contributed towards the drafting the work and the remaining authors contributed towards revising it critically for important intellectual content.

All authors gave final approval of the version to be published.

All authors agree to be accountable for all aspects of the work in ensuring that questions related to the accuracy or integrity of any part of the work are appropriately investigated and resolved.

Funding The work was funded by the Royal Marsden BRC. The funder reviewed the design of the project as a part of the award process. It did not have any influence in data collection and interpretation. It did not influence the drafting of the manuscript.

\section{Compliance with Ethical Standards}

Ethical Approval The study design was reviewed by the Human Research Authority and was granted ethical approval (UK Human Research Authority REC Reference 16/SC/0523).

Conflict of Interest The authors declare that they have no conflicts of interest to declare.

Full Study Protocol The full study protocol can be obtained from the funder's upon request from the Royal Marsden BRC.

\section{Appendix}

Table 5 Plasma neurotensin concentrations across diagnostic groups of biobanked plasma samples

\begin{tabular}{lll}
\hline Diagnosis & Number of cases & $\begin{array}{l}\text { Median plasma } \\
\text { neurotensin concentration } \\
\text { (pg/ml) (IQR) }\end{array}$ \\
\hline Normal & 46 & $338.9(214.9-467.6)$ \\
Diverticulosis & 9 & $321.3(203.6-495.2)$ \\
Colonic inflammation & 7 & $345.0(214.7-433.7)$ \\
Adenomatous poly (s) & 25 & $439.6(313.8-629.2)$ \\
Cancer & 8 & $549.3(344.5-1152.0)$ \\
\hline
\end{tabular}

Open Access This article is distributed under the terms of the Creative Commons Attribution 4.0 International License (http:// creativecommons.org/licenses/by/4.0/), which permits unrestricted use, distribution, and reproduction in any medium, provided you give appropriate credit to the original author(s) and the source, provide a link to the Creative Commons license, and indicate if changes were made.

\section{References}

1. The Office of National Statistics (2017) Office for National Statistics, Cancer survival by stage at diagnosis for England. https://www.ons. gov.uk/peoplepopulationandcommunity/healthandsocialcare/ conditionsanddiseases/bulletins/cancersurvivalinengland/ nationalestimatesforpatientsfollowedupto2017. Accessed 31 Jan 2019

2. National Institute of Health and Clinical Excellence (2015) Suspected cancer: recognition and referral. National Institute for Health and Care Excellence: Clinical Guidelines. https://www. nice.org.uk/guidance/ng12. Accessed 4 Feb 2019

3. Carraway R, Leeman SE (1973) The isolation of a new hypotensive peptide, neurotensin, from bovine hypothalami. J Biol Chem 248(19):6854-6861

4. Evers BM (2006) Neurotensin and growth of normal and neoplastic tissues. Peptides. 27(10):2424-2433. https://doi.org/10.1016/j. peptides.2006.01.028

5. Maoret JJ, Anini Y, Rouyer-Fessard C, Gully D, Laburthe M (1999) Neurotensin and a non-peptide neurotensin receptor antagonist control human colon cancer cell growth in cell culture and in cells xenografted into nude mice. Int J Cancer 80(3):448-454. https:// doi.org/10.1002/(SICI)1097-0215(19990129)80:3<448::AIDIJC19>3.0.CO;2-N

6. Maoret JJ, Pospai D, Rouyer-Fessard C, Couvineau A, Laboisse C, Voisin T et al (1994) Neurotensin receptor and its mRNA are expressed in many human colon cancer cell lines but not in normal colonic epithelium: binding studies and RT-PCR experiments. Biochem Biophys Res Commun 203(1):465-471

7. Souaze F, Viardot-Foucault V, Roullet N, Toy-Miou-Leong M, Gompel A, Bruyneel E et al (2006) Neurotensin receptor 1 gene activation by the Tcf/beta-catenin pathway is an early event in human colonic adenomas. Carcinogenesis. 27(4):708-716. https:// doi.org/10.1093/carcin/bgi269

8. Carraway RE, Plona AM (2006) Involvement of neurotensin in cancer growth: evidence, mechanisms and development of diagnostic tools. Peptides. 27(10):2445-2460. https://doi.org/10.1016/j. peptides.2006.04.030

9. Yoshinaga K, Evers BM, Izukura M, Parekh D, Uchida T, Townsend CM Jr, Thompson JC (1992) Neurotensin stimulates growth of colon cancer. Surg Oncol 1(2):127-134

10. Gui X, Guzman G, Dobner PR, Kadkol SS (2008) Increased neurotensin receptor-1 expression during progression of colonic adenocarcinoma. Peptides. 29(9):1609-1615. https://doi.org/10. 1016/j.peptides.2008.04.014

11. Kontovounisios C, Qiu S, Rasheed S, Darzi A, Tekkis P (2017) The role of neurotensin as a novel biomarker in the endoscopic screening of high-risk population for developing colorectal neoplasia. Updat Surg 69:397-402. https://doi.org/10.1007/s13304-0170464-6

12. Sgourakis G, Papapanagiotou A, Kontovounisios C, Karamouzis MV, Dedemadi G, Goumas C, Karaliotas C, Papavassiliou AG (2014) The combined use of serum neurotensin and IL-8 as screening markers for colorectal cancer. Tumour Biol 35(6):5993-6002. https://doi.org/10.1007/s13277-014-1794-3 
13. Fletcher RH (1986) Carcinoembryonic antigen. Ann Intern Med 104(1):66-73

14. Siegel R, Ma J, Zou Z, Jemal A (2014) Cancer statistics, 2014. CA Cancer J Clin 64(1):9-29. https://doi.org/10.3322/caac.21208

15. Lew J-B, St John DJB, Xu X-M, Greuter MJE, Caruana M, Cenin DR, He E, Saville M, Grogan P, Coupé VMH, Canfell K (2017) Long-term evaluation of benefits, harms, and cost-effectiveness of the National Bowel Cancer Screening Program in Australia: a modelling study. Lancet Public Health 2(7):e331-ee40. https:// doi.org/10.1016/S2468-2667(17)30105-6

16. Shapiro JA, Klabunde CN, Thompson TD, Nadel MR, Seeff LC, White A (2012) Patterns of colorectal cancer test use, including CT colonography, in the 2010 National Health Interview Survey. Cancer Epidemiol Biomark Prev 21(6):895-904. https://doi.org/ 10.1158/1055-9965.EPI-12-0192

17. Parra-Blanco A, Gimeno-Garcia AZ, Quintero E, Nicolas D, Moreno SG, Jimenez A et al (2010) Diagnostic accuracy of immunochemical versus guaiac faecal occult blood tests for colorectal cancer screening. J Gastroenterol 45(7):703-712. https://doi.org/ 10.1007/s00535-010-0214-8

18. Robbins E, Wooldrage K, MacRae E, Stenson I, Patel B, Pack K et al (2018) OTU-029 Faecal immunochemical tests (FIT) for surveillance after screening and polypectomy: an accuracy and efficiency study. Gut. 67(Suppl 1):A222

19. Gellad ZF, Stechuchak KM, Fisher DA, Olsen MK, McDuffie JR, Ostbye T et al (2011) Longitudinal adherence to fecal occult blood testing impacts colorectal cancer screening quality. Am J Gastroenterol 106(6):1125-1134. https://doi.org/10.1038/ajg.2011. 11

20. Ionescu MV, Carey F, Tait IS, Steele RJC (1998) Socioeconomic status and stage at presentation of colorectal cancer. Lancet 352(9138):1439. https://doi.org/10.1016/S0140-6736(98)00052-X

21. Frederiksen BL, Jorgensen T, Brasso K, Holten I, Osler M (2010) Socioeconomic position and participation in colorectal cancer screening. Br J Cancer 103(10):1496-1501. https://doi.org/10. 1038/sj.bjc.6605962

22. Sturgeon CM, Hoffman BR, Chan DW, Ch'ng SL, Hammond E, Hayes DF, Liotta LA, Petricoin EF, Schmitt M, Semmes OJ, Söletormos G, van der Merwe E, Diamandis EP, National Academy of Clinical Biochemistry (2008) National Academy of Clinical Biochemistry Laboratory medicine practice guidelines for use of tumor markers in clinical practice: quality requirements. Clin Chem 54(8):e1-e10. https://doi.org/10.1373/clinchem.2007. 094144

23. Church TR, Wandell M, Lofton-Day C, Mongin SJ, Burger M, Payne SR et al (2013) Prospective evaluation of methylated SEPT9 in plasma for detection of asymptomatic colorectal cancer. Gut. 63(2):317-325. https://doi.org/10.1136/gutjnl-2012-304149

24. Nichita C, Ciarloni L, Monnier-Benoit S, Hosseinian S, Dorta G, Ruegg C (2014) A novel gene expression signature in peripheral blood mononuclear cells for early detection of colorectal cancer. Aliment Pharmacol Ther 39(5):507-517. https://doi.org/10.1111/ apt. 12618

25. Huang Z, Huang D, Ni S, Peng Z, Sheng W, Du X (2010) Plasma microRNAs are promising novel biomarkers for early detection of colorectal cancer. Int J Cancer 127(1):118-126. https://doi.org/10. 1002/ijc. 25007
26. Parikh NI, Vasan RS (2007) Assessing the clinical utility of biomarkers in medicine. Biomark Med 1(3):419-436. https://doi.org/ 10.2217/17520363.1.3.419

27. Tanaka T, Tanaka M, Ishigamori R (2010) Biomarkers for colorectal cancer. Int J Mol Sci 11(9):3209-3225. https://doi.org/10.3390/ ijms 11093209

28. Holten-Andersen MN, Christensen IJ, Nielsen HJ, Stephens RW, Jensen V, Nielsen $\mathrm{OH}$ et al (2002) Total levels of tissue inhibitor of metalloproteinases 1 in plasma yield high diagnostic sensitivity and specificity in patients with colon cancer. Clin Cancer Res 8(1):156164

29. Babel I, Barderas R, Diaz-Uriarte R, Martinez-Torrecuadrada JL, Sanchez-Carbayo M, Casal JI (2009) Identification of tumorassociated autoantigens for the diagnosis of colorectal cancer in serum using high density protein microarrays. Mol Cell Proteomics 8(10):2382-2395. https://doi.org/10.1074/mcp. M800596-MCP200

30. Dupouy S, Viardot-Foucault V, Alifano M, Souaze F, Plu-Bureau G, Chaouat $M$ et al (2009) The neurotensin receptor-1 pathway contributes to human ductal breast cancer progression. PloS One 4(1):e4223. https://doi.org/10.1371/journal.pone.0004223

31. Souaze F, Dupouy S, Viardot-Foucault V, Bruyneel E, Attoub S, Gespach C et al (2006) Expression of neurotensin and NT1 receptor in human breast cancer: a potential role in tumor progression. Cancer Res 66(12):6243-6249. https://doi.org/10.1158/00085472.can-06-0450

32. Alifano M, Souaze F, Dupouy S, Camilleri-Broet S, Younes M, Ahmed-Zaid SM, Takahashi T, Cancellieri A, Damiani S, Boaron M, Broet P, Miller LD, Gespach C, Regnard JF, Forgez P (2010) Neurotensin receptor 1 determines the outcome of non-small cell lung cancer. Clin Cancer Res 16(17):4401-4410. https://doi.org/10. 1158/1078-0432.ccr-10-0659

33. Wang JG, Li NN, Li HN, Cui L, Wang P (2011) Pancreatic cancer bears overexpression of neurotensin and neurotensin receptor subtype-1 and SR 48692 counteracts neurotensin induced cell proliferation in human pancreatic ductal carcinoma cell line PANC-1. Neuropeptides 45(2):151-156. https://doi.org/10.1016/j.npep. 2011.01.002

34. Allen AE, Carney DN, Moody TW (1988) Neurotensin binds with high affinity to small cell lung cancer cells. Peptides. 9(Suppl 1): 57-61

35. Qiu S, Pellino G, Fiorentino F, Rasheed S, Darzi A, Tekkis P, Kontovounisios C (2017) A review of the role of neurotensin and its receptors in colorectal cancer. Gastroenterol Res Pract 2017: 6456257. https://doi.org/10.1155/2017/6456257

36. Poinot-Chazel C, Portier M, Bouaboula M, Vita N, Pecceu F, Gully D et al (1996) Activation of mitogen-activated protein kinase couples neurotensin receptor stimulation to induction of the primary response gene Krox-24. Biochem J 320(Pt 1):145-151

37. Wanebo HJ, Rao B, Pinsky CM, Hoffman RG, Stearns M, Schwartz MK, Oettgen HF (1978) Preoperative carcinoembryonic antigen level as a prognostic indicator in colorectal cancer. N Engl J Med 299(9):448-451. https://doi. org/10.1056/nejm197808312990904

Publisher's Note Springer Nature remains neutral with regard to jurisdictional claims in published maps and institutional affiliations. 